\title{
Weighing and Balancing in the Justification of Judicial Decisions
}

\author{
EVELINE T. FETERIS
}

\author{
Department of Speech Communication, Argumentation Theory and Rhetoric \\ University of Amsterdam \\ Spuistraat 134 \\ 1012 VB Amsterdam \\ Netherlands \\ e.t.feteris@uva.nl
}

\begin{abstract}
In legal theory, it is widely claimed that decisions in hard cases are based on weighing and balancing. However no reconstructions are given of the deep structure of the complex argumenation underlying the justification of these decisions. The author develops a model for the analysis of weighing and balancing of arguments in the justification of judicial decisions that are based on teleological-evaluative considerations. The justification is reconstructed as a complex argumentation that consists of different levels of argumentation and it is explained how these levels of argumentation relate to the burden of proof of a judge who gives a decision that is based on a weighing and balancing in which teleological-evaluative considerations are invoked.
\end{abstract}

Résumé: Il est largement accepté dans la théorie du droit que les décisions dans les procès difficiles se fondent sur un balancement d'arguments opposés. Toutefois on ne donne aucune reconstruction de la structure profonde de l'argumentation complexe qui sous-tend la justification des ces décisions. L’auteur développe une approche fondée sur les réflexions d'une évaluation téléologique pour analyser le balancement des arguments qui justifient les décisions judi-ciaires. La justification est reconstruite comme une argumentation complexe à différents niveaux, et on explique comment ces niveaux d'argumentation se relient à la charge de preuve d'un juge qui donne une décision fondée sur un ba-lancement dans lequel il invoque des réflexions d'évaluations téléologiques.

Keywords: goal argumentation, pragmatic argumentation, rationality, teleological argumentation, weighing and balancing.

\section{Introduction}

Judges often justify their decision by showing that the consequences of the decision are desirable in light of certain goals and values. Such a teleological-evaluative justification is often used when a judge has weighed a strict literal application of a rule and an application of the rule in a meaning that does more justice to the goals and values the rule is intended to realize.

A general problem with this form of justification is that in most cases judges only say that there were convincing reasons for application in accordance with the goals and values underlying the rule, but they do not go into the question of why these considerations carry more weight than the considerations underpinning a strict literal application. As various authors such as Alexy (2003a) and MacCormick and Summers (1991:529) contend, weighing and balancing is ubiquitous in law, but the

(C) Eveline T. Feteris. Informal Logic, Vol. 28, No. 1 (2008), pp. 20-30. 
way in which judges account for the way in which they have weighed arguments pro and contra is often poor. In most cases they only state that there were strong arguments one way, while the reason for considering them as weightier than the arguments for the other side is left unstated.

This problem becomes especially manifest when a judge uses his discretionary power to set aside a rule in its literal meaning in favour of an application in light of the purposes of the rule. If he only argues that there were strong arguments in favour of a teleological application in line with the goal of the rule, he leaves implicit a large part of the weighing: he leaves implicit the choices underlying the preference for a particular alternative on the basis of certain teleological-evaluative weighing criteria. From the perspective of the rationality of legal decision-making, however, it is important to make clear which choices are underlying the weighing and balancing. ${ }^{1}$

The aim of this paper is to develop an argumentation model for the reconstruction of weighing and balancing on the basis of teleologicalevaluative considerations. The model is intended as a heuristic and critical tool for the rational reconstruction of the justification of legal decisions. From the perspective of a rational discussion it makes explicit the choices underlying the weighing and balancing so that they can be made explicit and submitted to rational critique.

To this end, in section 2, I will go into the justification of weighing on the basis of teleological-evaluative considerations from the perspective of legal theory. Then, in section 3, I will develop the argumentation model in which I specify the way in which the argumentation can be reconstructed from the perspective of the burden of proof of a judge who takes a decision on the basis of a weighing on the basis of teleological-evaluative considerations.

\section{The justification on the basis of teleological-evaluative considerations as a form of weighing and balancing}

To establish what the burden of proof in the context of a weighing on the basis of teleological-evaluative considerations exactly amounts to, first it is important to determine what the rationale is for the use of goals in the application and interpretation of legal rules and how a justification on the basis of these considerations can be conceived as a form of weighing and balancing.

\footnotetext{
${ }^{1}$ Also from the perspective of the convincingness of the justification it is important that the judge mention not only the arguments pro. From persuasion research (O'Keefe 2002:219-221), it emerges that a message that also contains the refutation of contraarguments is considered to be more persuasive than a message that only mentions contra-arguments.
} 


\subsection{The rationale for the use of goals in the application and interpretation of legal rules}

The rationale for justifying a decision by referring to the goal or purpose of the rule can be found in considering legal rules as an instrument for realizing certain legal, social and economic goals. As Fuller (1958, p. 665) states it, the meaning of a legal rule should be established on the basis of the good the rule aims to promote or the evil it seeks to avert. Legal rules are designed to promote certain goals and values that are considered essential from the perspective of justice or public good. Various authors in legal philosophy and legal theory such as Bell (1983), Eskridge (1994), Fuller (1948, 1958), Lyons (1993), MacCormick and Summers (1991, pp. 518-519), Nozick (1993, pp. 133 ff), Summers (1978), Wróblewski (1992, pp. 103-107) contend that in the application of legal rules judges should apply and interpret them in such a way that the consequences are conducive to realizing such goals and values. The purpose of a statute so understood forms an evaluative ground for considering the consequences of possible interpretations as favourable or unfavourable for realizing the postulated purpose. Application of a rule that would lead to consequences that are contrary to its purposes would be undesirable from this purpose.

Normally the starting point from the perspective of legal certainty is that the judge applies the law, doing justice to the intention of the legislator who has weighed and balanced the relevant interests. This implies that the judge must, in the absence of overriding considerations, apply the rule in the strict literal sense. However, if application would lead to consequences that would be incompatible with the goals and values the legislator wanted to achieve with the rule, the judge can make an exception. The idea is that a rational legislator cannot have wanted that application of a rule would lead to consequences that would be incompatible with the goal of the rule. By referring to the goals and values in relation to the circumstances of the concrete case, the judge can explain how the original weighing of interests from the perspective of the goal of the rule formulated by the legislator must be 'translated' to the new situation so that it would result in a new formulation of the rule in which an exception is made for the concrete case. ${ }^{2}$ He must explain that in the concrete case, application of the rule in an amended meaning would be more acceptable from the perspective of the underlying goals, principles and values than application in the strict literal meaning. ${ }^{3}$

From the perspective of the rationality of legal decision-making making an exception implies that a judge who takes a decision on the basis of

\footnotetext{
${ }^{2}$ This situation differs from the situation in the context of constitutional interpretation where the judge replaces the weighing performed by the legislator with his own weighing (cf. Alexy 2003a and 2003b).

${ }^{3}$ This obligation corresponds with the hierarchy of interpretation methods as described by MacCormick and Summers (1991:528-529) which implies that a judge who chooses a teleological-evaluative interpretation must justify why he departs from the literal meaning by showing that a literal application would lead to an absurd result.
} 
such a weighing is obliged to explain why the exception is justified in the concrete case.

\subsection{Weighing and balancing}

Now it has become clear what a weighing and balancing on the basis of goals and values exactly amounts to, I will go into the question of what views in the legal literature about weighing and balancing are relevant for answering the question what the burden of proof for a weighing on the basis of teleological-evaluative considerations exactly amounts to. I will go into the question of what weighing is exactly, when it is necessary and allowed, and how it must be justified.

According to scholars in legal theory, the choice between a literal interpretation and a teleological interpretation can be considered as a specific form of a weighing of arguments. ${ }^{4}$ In their discussion of the results of a research project into methods of interpretation carried out in nine countries, MacCormick and Summers (1991:528, 485-486) distinguish various patterns of justification. One of these patterns is the weighing of arguments. In their terms, a weighing of a strict literal and a teleological interpretation occurs when a judge cannot rely on an existing rule (such as a priority rule) on the basis of which one argument has preference over another argument. In legal systems where there is no clear statutory rule on the basis of which he can solve a conflict between a literal interpretation with an absurd consequence and a teleological interpretation with a desirable consequence, he will have to weigh the consequences of both interpretations. ${ }^{5}$

Regarding the justification of a weighing and balancing, a judge must specify which interests are weighed against each other, and he must specify how they are weighed. The judge must be clear about the exact content of the interests at stake and about the relative weight of these interests. For constitutional interpretation, Alexy (2003a, pp. 436 ff) explains that the balancing of interests is based on the principle of proportionality, which requires that a judge who wants to violate a constitutional right and is of the opinion that certain interests should have more weight than other interests, has a burden of proof to justify why this is the case. This implies that he must first specify the weighing rule on the basis of which such a weighing can be justified. Then he must explain how the weighing rule must be applied in the concrete case and what the result of this application is. This amounts to specifying what the interests are and the relative weights of the interests.

\footnotetext{
${ }^{4}$ See also authors who represent an approach that belongs to the tradition of artificial intelligence and law such as Hage (1997:124-125), Hage and Sartor (2003), Prakken and Sartor (2004), Verheij (1996:59-60).

5. As is described in MacCormick and Summers (1991:528, 485-486), in countries such as Germany and Italy there is an explicit rule that allows a judge to make an exception on the basis of an absurd result.
} 


\subsection{The justification of weighing and balancing}

As we have seen, for a complete justification on the basis of goals and values, the judge must give a complex justification consisting of two components.

The first component consists of a specification and justification of the 'weighing rule' on the basis of which the judge has preferred an alternative that does justice to the requirement of reasonableness and fairness to the alternative that does justice to the requirement of legal certainty. In order to comply with this obligation, the judge will have to make clear that he has used a weighing rule that implies that the application of a rule that has consequences that are desirable from the perspective of the goal of the rule is to be preferred to the application of a rule that has undesirable consequences from that perspective. ${ }^{6}$

The second component consists of a justification of the result of the application of the weighing rule in the concrete case. This involves the following:

(i) The judge must show that the application in a meaning amended on the basis of the goal of the rule would lead to certain consequences in the concrete case.

(ii) The judge must show that in the circumstances of the concrete case those consequences are desirable from the perspective of the goal of the rule.

(iii) The judge must show that the goal of the rule is underlying the branch of law the rule belongs to.

(iv) The judge must show that a strict literal application would lead to certain consequences in the concrete case.

(v) The judge must show that in the circumstances of the concrete case those consequences are undesirable from the perspective of the goal of the rule.

(vi) The judge must, as in (iii), show that the goal of the rule is underlying the branch of law the rule belongs to.

(vii) The judge must specify the relevant circumstances of the concrete case that justify the exception to the rule.

\section{A reconstruction of weighing and balancing on the basis of goals and values from a pragma-dialectical perspective}

From a pragma-dialectical perspective, argumentation based on a weighing and balancing must be reconstructed as part of a critical discussion. ${ }^{7}$ This implies that it must reflect the dialogical context in

\footnotetext{
${ }^{6}$ From the perspective of a deep justification, a further justification of this rule can be required. In that case the judge will have to specify on which legal-philosophical grounds the consequences in relation to the goal of the rule may constitute an overriding reason for choosing a particular application of a rule.

${ }^{7}$ The terms "pragma-dialectical" and "critical discussion" used here are technical terms of the "pragma-dialectical" theory of argumentation introduced by van Eemeren and
} 
which the judge justifies his decision against certain forms of critique. Therefore the reconstruction must reflect, first, the complexity of the argumentation in relation to the nature of the dispute and, second, the way in which the judge reacts to or anticipates various forms of rational critique. In what follows, I will describe how the complex argumentation can be modelled so as to clarify the underlying choices and levels in the justification that must be made explicit from the perspective of the judge's burden of proof.

\subsection{A pragma-dialectical analysis of weighing and balancing}

A judge who weighs two alternative applications of a legal rule does this in the context of a "mixed dispute" in which one party argues that a particular rule should be applied in the concrete case and the other party argues that this rule should not be applied. ${ }^{8}$ This implies that the reconstruction on the level of the main argumentation should reflect the choice between the rival points of view of the parties in dispute and should therefore reflect the balancing of the two positions on the basis of desirable and undesirable consequences in relation to the purpose of the rule.

If a judge chooses the application of a rule $\mathrm{X}$ in a specific interpretation, $X^{\prime}$ and rejects the opposite view, to apply $X$ in an alternative interpretation, $\mathrm{X}^{\prime \prime}$, his main standpoint must express a preference for $\mathrm{X}^{\prime}$ above $\mathrm{X}^{\prime \prime}$ :

1 In the circumstances of the concrete case $(\mathrm{C} 1, \mathrm{C} 2, \ldots, \mathrm{Cn})$ application of rule $\mathrm{R}$ in the amended meaning $\mathrm{R}^{\prime}$ is to be preferred to application in the strict literal meaning $\mathrm{R} "$

To make clear that the argumentation on the main level consists of a weighing of different alternatives, a complex coordinative argumentation must be reconstructed:

1.1a In the circumstances of the concrete case C1, C2, .., Cn, application of rule $\mathrm{R}$ in interpretation $\mathrm{R}$ ' leads to $\mathrm{Y}^{\prime}$.

$1.1 \mathrm{~b} \mathrm{Y}^{\prime}$ is desirable.

1.1c In the circumstances of the concrete case C1, C2, ..., Cn, application of rule $\mathrm{R}$ in interpretation $\mathrm{R}$ " leads to $\mathrm{Y}^{\prime \prime}$.

1.1d $\mathrm{Y}^{\prime \prime}$ is undesirable.

The complementing argument in which the balancing of the two alternatives is expressed can be reconstructed as follows:

1.1e If application of rule $\mathrm{R}$ in interpretation $\mathrm{X}^{\prime}$ in the circumstances of the concrete case $\mathrm{C} 1, \mathrm{C} 2, . . ., \mathrm{Cn}$ leads to $\mathrm{Y}^{\prime}$, and $\mathrm{Y}^{\prime}$ is desirable, and

Grootendorst (see 2004 for its latest formulation). -Eds.

${ }^{8}$ For a description of the structure of various forms of disputes, see van Eemeren and Grootendorst (1992 Chapter 2). 


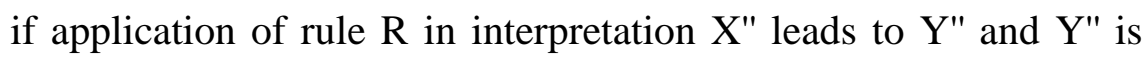
undesirable, then application of rule $\mathrm{R}$ in interpretation $\mathrm{X}^{\prime}$ is to be preferred to application of rule $\mathrm{R}$ in interpretation $\mathrm{X}$ ”.

By reconstructing the main argumentation from the perspective of the discussion context it can be made clear that it concerns a complex argumentation in which a choice between two alternatives is justified. Often part of this argumentation remains implicit, so the reconstruction is aimed at making explicit which arguments underlie the weighing so that they can be submitted to critique. This reconstruction makes explicit that the argumentation on the main level consists of various elements that must each be supported by further argumentation:

- Argument 1.1b must be supported by showing that the consequences of the preferred alternative $\mathrm{R}$ ' in the circumstances of the concrete case are desirable from the perspective of the goal of the rule. ${ }^{9}$

- Argument 1.1d must be supported by showing that the consequences of the rejected alternative $\mathrm{R}$ " in the circumstances of the concrete case are undesirable from the perspective of the goal of the rule.

- Argument 1.1e must be supported by making clear on which underlying considerations it is based.

Of course, also the arguments 1.1a and 1.1.c must be supported, but because this support concerns empirical statements that are not based on legal considerations, it is not of our concern here.

In what follows, in 3.2, I will first discuss the way in which the desirability of the consequences of $\mathrm{R}^{\prime}$ and the undesirability of the consequences of $\mathrm{R}^{\prime \prime}$ can be justified from the perspective of the goal of the rule. Then, in 3.3, I will discuss how the weighing rule can be justified.

3.2 The justification of the desirability of the consequences of $R^{\prime}$ and the undesirability of the consequences of $R$ " from the perspective of the goal of the rule

As concerns the justification of $1.1 \mathrm{~b}$ and 1.1d, in earlier publications (Feteris 2005) I have specified what the burden of proof of a judge who puts forward teleological-evaluative argumentation exactly amounts to. On the level of the sub-argumentation in support of $1.1 \mathrm{~b}$ respectively $1.1 \mathrm{~d}$, the judge must specify why the consequences of application in the concrete case of R' are desirable and why the consequences of R" are undesirable in light of the goal of the rule:

\footnotetext{
${ }^{9}$ The circumstances of the concrete case can be considered as what Hage, Prakken and Sartor call 'factors': the relevant circumstances of the case that can be considered as reasons for applying or not applying a rule in a concrete case on the basis of their 'link' with the goal of the rule. In their view the justificatory force of such a rule is based on the 'teleological link' between the factors and the conclusion (see Prakken and Sartor 2004:133.134).
} 
1.1b Consequence $\mathrm{Y}^{\prime}$ is desirable in the circumstances $\mathrm{C} 1, \mathrm{C} 2, \ldots$ of the concrete case.

1.1b.1a Consequence $\mathrm{Y}^{\prime}$ is compatible with goal $\mathrm{G}$.

1.1b.1b Goal $\mathrm{G}$ is a rational goal that underlies the legal system.

1.1d Consequence $\mathrm{Y}^{\prime \prime}$ is undesirable in the circumstance C1, C2, ... of the concrete case.

1.1d.1a Consequence $Y^{\prime \prime}$ is incompatible with goal G.

1.1d.1b Goal $\mathrm{G}$ is a rational goal that underlies the legal system.

For a further justification of $1.1 \mathrm{~b} .1 \mathrm{~b} / 1.1 \mathrm{~d} .1 \mathrm{~d}$, further supporting argumentation is required in which it is specified why goal $\mathrm{G}$ is a rational goal that underlies the legal system. The judge can do this by referring to the principles and values that underlie the rule and to the relevant part of the legal system:

1.1b.1b/1.1d.1b

Goal $\mathrm{G}$ is a rational goal that underlies the legal system

1.1b.1b.1/1.1d.1b.1 Goal G is compatible with the following general legal principles and values $\mathrm{P}$....

The existence of the principles and values 1.1b.1b.1/1.1d.1b.1 must, in their, turn be justified by referring to the rules that they 'support' and by referring to authoritative legal decisions in which these principles and values are expressed:

\section{1b.1b.1/1.1d.1b.1 Goal $G$ is compatible with the following general legal principles and values $\mathrm{P}$... . \\ 1.1b.1b.1.1/1.1d.1b.1.1 The general legal principles and values $P$ are underlying the rules $\mathrm{r} 1, \mathrm{r} 2, \ldots, \mathrm{rn}$ and are formulated in the legal decisions $\mathrm{d} 1, \mathrm{~d} 2$, $\ldots, \mathrm{dn}$.}

The quality of the justification of the (un)desirability of the consequences expressed in 1.1b and 1.1d finally depends on the question whether the goals mentioned by the judge are based on certain principles and values underlying the legal system and are expressed in certain legal rules and authoritative legal decisions.

\subsection{The justification of the weighing rule}

Finally, the judge must justify why the chosen alternative is to be preferred to the other. In the legal theoretical literature on weighing and balancing, there is a comunis opinio that a balancing must always take place on the basis of certain criteria. These criteria are applied to the relevant circumstances of the concrete case, with the result that why one result is more desirable than the other can be accounted for. Although the judge gives a decision about the balancing of interests in a concrete case, the authors agree that the considerations underlying the application of the 
criteria in the concrete case must also be applicable to similar cases. On the basis of the requirement of universalizability, the judge must show that the application of the criteria would lead to a similar result in similar cases. The weight attached to certain considerations is not limited to the concrete case but is also applicable in similar (future) cases. For this reason, according to authors such as Alexy (2003a, 2003b), the judge must explain on which general rule the preference for a particular application of the rule is based.

Because a weighing and balancing on the basis of goals and values is not based on an existing rule, the judge must, as we have seen, formulate the rule on the basis of which he attaches more weight to the arguments for $\mathrm{R}^{\prime}$ than to the arguments for $\mathrm{R}$ ". The complementing argument expressing the rule that is necessary to make the argumentation complete can be reconstructed as follows:

1.1e If, in the circumstances of the concrete case $\mathrm{C} 1, \mathrm{C} 2, \ldots, \mathrm{Cn}$, the application of rule $\mathrm{R}$ in the meaning $\mathrm{R}^{\prime}$ leads to the desirable consequence $\mathrm{Y}^{\prime}$ that is compatible with goal $\mathrm{G}$ and the application

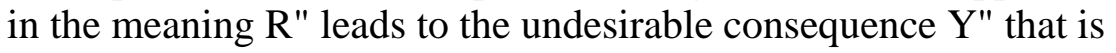

incompatible with goal $G$, then the application in the meaning $\mathrm{R}^{\prime}$ is to be preferred to the application in the meaning $\mathrm{R} "$

For the circumstances of the concrete case, the judge will have to clarify the content of this general rule 1.1e by specifying what constitute desirable consequences from the perspective of a particular goal $G$ and what can be considered relevant 'factors' that can function as arguments for the application in a particular meaning. Such a rule must specify which factors in the concrete case are relevant from the perspective of the goal of the rule. It must justify that the application of the rule in the meaning $\mathrm{R}^{\prime}$ in the circumstances of the concrete case is more desirable than its application in the meaning $\mathrm{R} "$.

\section{Conclusion}

In this contribution I have given a reconstruction of the burden of proof of a judge who weighs arguments for and against a particular application of a legal rule on the basis of goals from a pragma-dialectical perspective. I have shown how the judge can live up to his burden of proof by specifying the content and structure of the complex argumentation he must put forward in the justification of his decision. From a pragma-dialectical perspective, in a complete justification the main argumentation consists of three elements: the two alternative applications that have been weighed against each other and the weighing rule that has been applied. The evaluation of the two alternatives must be supported by a complex argumentation consisting of three levels of arguments in which the judge must explain why the consequences of the preferred alternative are desirable in the concrete case and why the consequences of the rejected alternative are undesirable in the concrete 
case from the perspective of the goal of the rule. Furthermore the rule on which the weighing is based must be made explicit for the concrete case.

From a legal philosophical and legal theoretical perspective the reconstruction of the choices underlying the decision explain how the judge has used his discretionary space in the interpretation and application of legal rules. The importance of making explicit the underlying choices lies in the fact that in legal practice often large parts of the argumentation remain implicit and it is not clear which choices underlie the decision. The model for the reconstruction offers a heuristic tool to make these choices explicit from the perspective of the burden of proof of the judge with respect to his justification. On the basis of the reconstruction with the aid of the model it can be made clear which parts of the argumentation that are left implicit (sometimes for strategic reasons) belong to the commitments of the judge and must be submitted to critique.

\section{References}

Alexy, R. (2003a). 'On balancing and subsumption. A structural comparison'. Ratio Juris. Vol. 16, No. 4, pp. 433-449.

Alexy, R. (2003b). 'Constitutional rights, balancing, and rationality'. Ratio Juris. Vol. 16, No. 2, pp. 131-140.

Bell, J. (1983). Policy arguments in judicial decisions. Oxford: Clarendon Press.

Eemeren, F.H. van, and R. Grootendors. (1992). Argumentation, Communication and Fallacies. Hillsdale, NJ: Lawrence Erlbaum.

Eemeren, F.H. van and R. Grootendorst (2004). A systematic theory of argumentation. The pragma-dialectical approach. Cambridge: Cambridge University Press.

Eskridge, W.N. Jr. (1994). Dynamic statutory interpretation. Cambridge, MA: Harvard University Press.

Feteris, E.T. (2002). 'A pragma-dialectical approach of the analysis and evaluation of pragmatic argumentation in a legal context'. Argumentation, Vol. 16, No. 3, pp. 349-367.

Feteris, E.T. (2003). 'The rational reconstruction of pragmatic argumentation in a legal context: the analysis and evaluation of teleological argumentation'. In: F.H. van Eemeren, J.A. Blair, C.W. Willard (eds.), Proceedings of the fifth ISSA conference on argumentation. Sicsat, Amsterdam.

Feteris, E.T. (2004). 'Arguments from unacceptable consequences and a reasonable application of law'. In: J.A. Blair, D. Farr, H.V. Hansen, R.H. Johnson, C.W. Tindale (eds.), Informal Logic@25. Windsor, ON: OSSA (CD-ROM)

Feteris, E.T. (2005). 'The rational reconstruction of argumentation referring to consequences and purposes in the application of legal rules'. Argumentation, Vol. 19, No. 4, pp. 459-470.

Fuller, L. (1948). 'The case of the Speluncean Explorers' law'. Harvard Law Review, Vol. 62. 
Fuller, L. (1958). 'Positivism and the fidelity to law-A reply to professor Hart'. Harvard Law Review, Vol. 71, pp. 630-672.

Gerards, J.H. (2006). 'Rechterlijke belangenafweging in het publiekrecht'. Rechtsgeleerd Magazijn Themis, jrg. 167, nr. 4, pp. 147-159.

Gottlieb, G. (1968). The logic of choice: An investigation of the concepts of rule and rationality. London: Allen and Unwin.

Hage, J. (1997). Reasoning with rules, An essay on legal reasoning and its underlying logic. Dordrecht etc.: Kluwer.

Hage, J. and G. Sartor (2003). 'Legal theory construction'. Associations.

Lyons, D. (1993). Moral aspects of legal theory. Essays on law, justice, and political responsibility. Cambridge: Cambridge University Press.

MacCormick, D.N. (1978). Legal reasoning and legal theory. Oxford: Clarendon Press.

MacCormick, N and R.S. Summers. (1991). Interpreting statutes. A comparative study, Aldershot etc.: Dartmouth.

Nozick, R. (1993). The nature of rationality. Princeton: Princeton University Press.

O'Keefe, D.J. (2002). Persuasion, Theory and research. Thousand Oaks, CA: Sage.

Pontier, J.A. and E. Burg. (2004). EU Principles on jurisdiction and recognition and enforcement of judgments in civil and commercial matters according to the case law of the European Court of Justice The Hague: Asser Press.

Prakken, H.and G. Sartor. (2004). 'The three faces of defeasibility in the law'. Ratio Juris, Vol. 17, No. 1, pp. 118-139.

Smits, J.M. (2006). 'Belangenafweging door de rechter in het vermogensrecht: een kritische beschouwing'. Rechtsgeleerd Magazijn Themis, jrg. 167, nr. 4, pp. 134-140.

Summers, R.S. (1978). 'Two types of substantive reasons: The core of a theory of Common-Law justification'. Cornell Law Review, 63, pp. 707-788.

Verheij, B. (1996). Rules, reasons, arguments, Formal studies of argumentation and defeat. Dissertation Universiteit Maastricht.

Wróblewski, J. (1992). The judicial application of law. (Edited by Zenon Bankowski and Neil MacCormick). Dordrecht etc.: Kluwer. 